\title{
The effect of vitamin A upon the cerebrospinal-fluid pressures of young rabbits suffering from hydrocephalus due to maternal hypovitaminosis $\mathrm{A}$
}

\author{
By J. W. MILLEN \\ Anatomy School, University of Cambridge \\ AND A. D. DICKSON \\ Department of Anatomy, University of Aberdeen \\ (Received 24 May 1957)
}

The role of vitamin A deficiency in producing lesions of the central nervous system has interested investigators since attention was first drawn by Hart, Miller \& McCollum (I9I6) to a syndrome of ataxia, muscular incoordination and paralysis occurring in pigs fed on a diet deficient in vitamin A. Amongst the effects noted by several workers (Moore \& Sykes, I940; Mellanby, I940-1) has been an increased cerebrospinal-fluid pressure sometimes associated with hydrocephalus. The increased cerebrospinalfluid pressure has, however, generally been regarded as a secondary effect due to compression of the central nervous system produced by disorganized growth of the bony coverings of the brain and spinal cord. For the most part these experiments have been carried out on young animals subjected to a gross vitamin A deficiency after birth. Recently, however, it was found that the young born to female rabbits fed on a vitamin A-deficient diet for 24 weeks before and during pregnancy suffered from a congenital hydrocephalus accompanied by an increased cerebrospinal-fluid pressure. When the period of deficiency was shorter the cerebrospinal-fiuid pressure was increased, but the animals were not hydrocephalic (Millen \& Woollam, 1956). In the young hydrocephalic animals the vault of the skull was expanded and the anterior fontanelle was widely open. It seemed unlikely therefore that the increased cerebrospinal-fluid pressure could be secondary to bony compression of the brain, and the hypothesis was put forward that the increased pressure was the primary event. It appeared further that an overproduction of cerebrospinal fluid might be responsible for the rise in pressure.

The work reported in this paper was carried out to determine the effect of vitamin A on the cerebrospinal-fluid pressures of live-born hydrocephalic young rabbits.

\section{EXPERIMENTAL}

Twenty-eight hydrocephalic young rabbits were used in the experiment. These young were born to female rabbits maintained on a pellet ration, containing less than $\mathrm{I} \mu \mathrm{g}$ carotene/g, for various periods before mating (Lamming, Woollam \& Millen, 1954). The young were fed on the same diet after weaning. Each adult rabbit received 
$25 \mathrm{mg} \alpha$-tocopheryl acetate and 750 i.u. vitamin D weekly. The diagnosis of hydrocephalus was based on the presence of a persistent anterior fontanelle in the young at 7 days of age. The intraventricular pressure was measured, under ether anaesthesia, by means of a bubble manometer when the animal was from 8 to $5^{6}$ days old. Further pressure measurements were made at intervals of about $\mathrm{I}$ week.

With four exceptions, the initial intraventricular-pressure measurement was combined with the introduction of air for ventriculography. A three-way tap, one outlet of which was attached to a $2 \mathrm{ml}$. syringe, was inserted between the needle and the manometer. Immediately after the intraventricular-pressure measurement a small quantity of cerebrospinal fluid was withdrawn and replaced by air, the procedure being repeated until a total amount of between 0.5 and $\mathrm{r} .5 \mathrm{ml}$. of air had been introduced. Lateral X-rays of the head enabled the size of the dilated ventricles to be assessed. After the initial pressure measurement 10,000-20,000 i.u. synthetic vitamin A acetate were given by mouth or by subcutaneous injection, and this dose was repeated at weekly intervals.

\section{RESULTS}

All the hydrocephalic animals exhibited increased cerebrospinal-fluid pressures. The giving of vitamin $A$ to the hydrocephalic young led to a rapid fall in the cerebrospinalfluid pressure determined by intraventricular puncture. As a rule the pressure continued to fall steadily and reached normal limits within 3-4 weeks from the beginning of treatment. The results are shown diagrammatically in Figs. I and 2. Intraventricular puncture only was performed in the animals whose cerebrospinal-fluid pressures
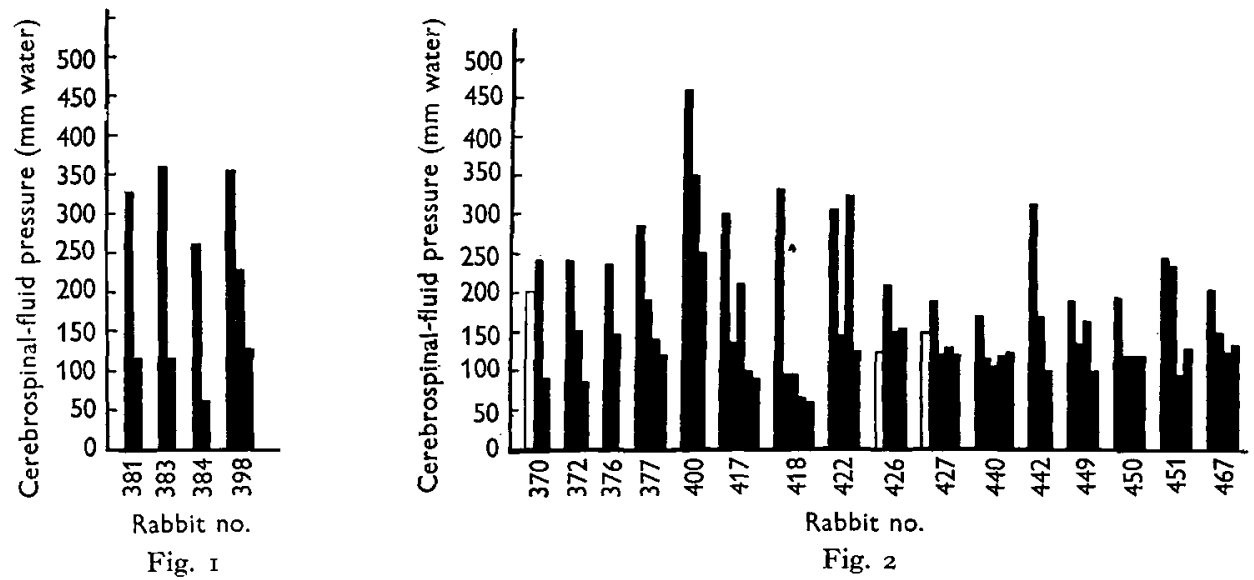

Fig. 1. Effect of vitamin A on cerebrospinal-fluid pressures of young hydrocephalic rabbits suffering from hypovitaminosis A. Intraventricular puncture only. Each column represents a cerebrospinalfluid pressure measurement. The interval between measurements was 75 days in rabbits nos. $38 \mathrm{r}$, 383 and 384 and $I$ week in rabbit no. 398 . Vitamin $A$ was given after the initial measurement.

Fig. 2. Effect of vitamin $A$ on cerebrospinal-fluid pressures of young hydrocephalic rabbits suffering from hypovitaminosis A. Intraventricular puncture and ventriculography. Each column represents a cerebrospinal-fluid pressure measurement. The interval between measurements was about $\mathrm{I}$ week. Vitamin A was given after the initial measurement except in three animals. In these animals vitamin $A$ was withheld until after the second measurement and the first pressure reading is shown as a blank column. 
are recorded in Fig. I, whereas the pressures shown in Fig. 2 are for animals in which ventriculography was also carried out. There appeared to be no difference in the efficiency of vitamin A given by mouth or subcutaneous injection, but the number of animals treated was too small to permit an unequivocal answer to this question. Pressure measurements were discontinued when readings within normal limits were obtained, and further progress was judged by the closure of the anterior fontanelle and the general well-being of the animal. In three rabbits weekly pressure measurements were not carried out, a second estimation being deferred until the animals were over 2 months old. Readings within the normal range were then obtained from these animals.

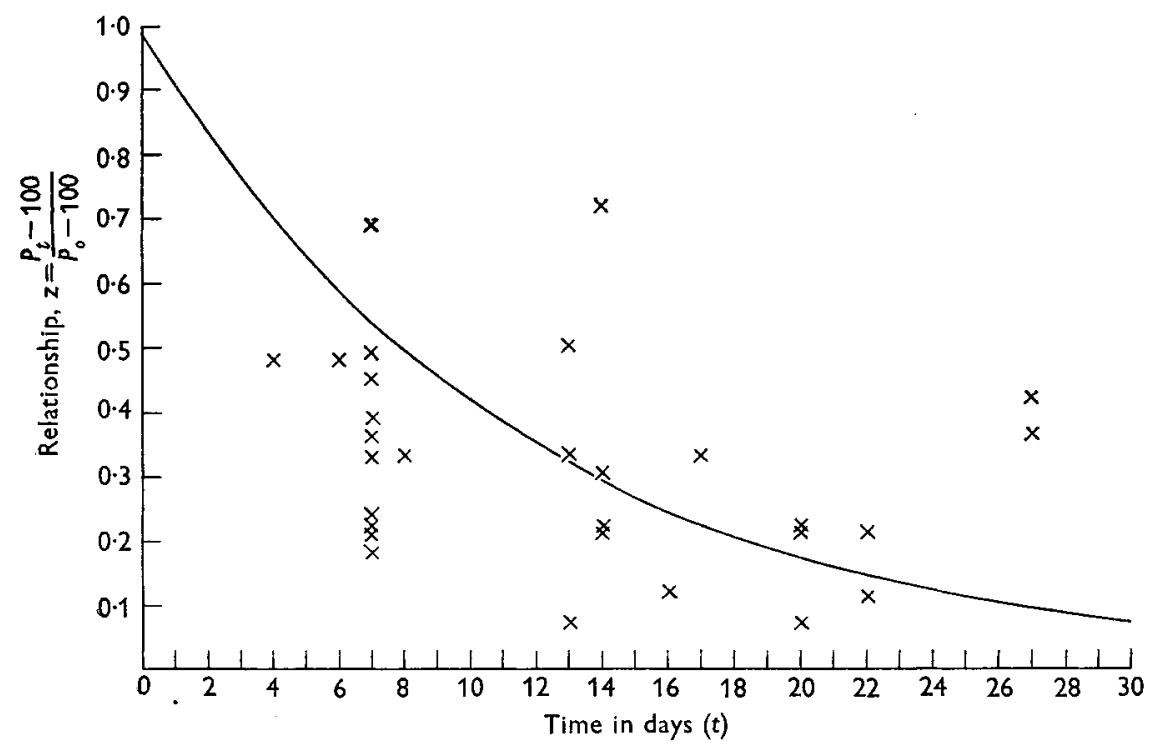

Fig. 3. Relationship between cerebrospinal-fluid pressure of young hydrocephalic rabbits suffering from hypovitaminosis $A$ and duration of treatment with vitamin $A$. The ratio of the pressure in excess of $100 \mathrm{~mm}$ water to the initial excess of pressure is plotted against length of time, in days, for which treatment was carried out. Further details are given on p. 443 .

In three animals, in which the initial cerebrospinal-fluid pressures were $200 \mathrm{~mm}$ water or below, vitamin A was withheld for a week. (The initial pressure measurements in these animals are represented by blank columns in Fig. 2.) At the end of this time the pressures were found to have increased and vitamin A therapy was begun. The cerebrospinal-fluid pressures then began to fall, as in the other animals.

Eight animals with initial pressures ranging from 190 to $4 \mathrm{IO} \mathrm{mm}$ water died before a second measurement was made. These animals included several of those on which the early attempts at ventriculography were made. Death appeared to be due to the too rapid and excessive removal of cerebrospinal fluid before the replacement by air and, as already noted, in subsequent operations the replacement was carried out in several steps.

A statistical analysis of the results showed that there was a highly significant drop in the cerebrospinal-fluid pressures after $6-7$ days of treatment and that the pressures 
ultimately stabilized at about $100 \mathrm{~mm}$ water. Denoting by $P_{t}$ the pressure after $t$ days, and by $P_{o}$ the initial pressure, the quantity $z=\frac{P_{t}-100}{P_{0}-100}$ was plotted against $t$ (Fig. 3). It might seem natural to expect that $z$ decreases to zero exponentially with $t$, and the best fitted curve, to $z=e^{-0.088 t}$, is shown in Fig. 3. It was found, however, that this formula did not adequately represent the decrease in pressure, the mean value of $z$ at $t=7$ days being significantly lower than the value given by the exponential curve.

Of the twenty-eight hydrocephalic animals treated with vitamin A, nine still survive. Six of them are over 12 months old and have remained in good health. They are indistinguishable on examination from control animals of the same age. Various causes were responsible for the deaths of animals used in the experiment. In some death occurred accidentally during anaesthesia, in others intracranial haemorrhage succeeded the removal of cerebrospinal fluid or injury to a cerebral blood vessel. Still others succumbed to infection of the lungs. These causes, however, did not account for all the deaths among the experimental animals. Some animals, in general those with initial cerebrospinal-fluid pressures of $300 \mathrm{~mm}$ or more of water, failed to survive for more than 4-7 weeks after birth. In these young the amount of cerebral damage was perhaps so great as seriously to interfere with their general well-being and survival.

\section{DISCUSSION}

The finding of considerably increased cerebrospinal-fluid pressures in the hydrocephalic animals is in agreement with previous observations upon the effects of a hypovitaminosis $\mathrm{A}$ on the cerebrospinal-fluid pressure in rabbits (Millen \& Woollam, 1956) and in other animals (Moore \& Sykes, 1940; Eveleth, Bolin \& Goldsby, r949; Sorensen, Kowalczyk \& Hentges, 1954; Woollam \& Millen, 1956). It also accords with the view put forward in a previous paper (Millen \& Woollam, 1956) that the increase in the cerebrospinal-fluid pressure is the immediate effect of the hypovitaminosis A and that hydrocephalus occurs in consequence of this increase.

There seems to be little doubt that the rapid fall in the cerebrospinal-fluid pressure was a direct result of giving vitamin $A$ to the animals. It might be argued that the carrying out of ventriculography was a factor in lowering the cerebrospinal-fluid pressure. But against this argument can be put the similar reductions of pressure observed in those animals in which ventriculography was not performed (Fig. I). Further, in three animals vitamin $A$ was withheld for I week after ventriculography and the cerebrospinal-fluid pressure was higher at the second reading than at the first (Fig. 2).

The reductions in the cerebrospinal-fluid pressures produced by vitamin $\mathrm{A}$ in rabbits suffering from congenital hydrocephalus parallel similar findings in young animals subjected to a vitamin A-deficient diet after birth. In deficient calves Helmboldt, Jungherr, Eaton \& Moore (1953) recorded values for cerebrospinal-fluid pressure of $220-380 \mathrm{~mm}$ water, which fell to $159-\mathrm{I} 18 \mathrm{~mm}$ after $2-4$ weeks treatment with vitamin A. Sorensen $e t$ al. (1954) were able to produce substantial reductions 
in cerebrospinal-fluid pressure in vitamin A-deficient pigs by giving them a carotene supplement.

Few reports have appeared on the effects of gross vitamin A deficiency in infants, but the findings do strongly support the view that the cerebrospinal-fluid pressure is increased in hypovitaminosis $\mathrm{A}$ and that a rapid reduction in pressure can be brought about by administering vitamin A. Cornfeld \& Cooke (1952) described an infant aged $5 \frac{1}{2}$ months who had been fed on an artificial diet deficient in vitamin A. Lumbar puncture revealed a cerebrospinal-fluid pressure of $280 \mathrm{~mm}$ water, the anterior fontanelle was bulging and the sutures of the skull were separated. Xerophthalmia was also present. Treatment with large doses of vitamin A produced amelioration. Recently, Bass \& Caplan (1955) recorded two cases of gross vitamin A deficiency in infants associated with increased intracranial pressure. A 7 -month infant, who had received from the age of $I$ month a diet lacking in vitamin $A$, was admitted to hospital with severe keratitis and marked bulging of the anterior fontanelle. Two days after the beginning of treatment with 100,000 i.u. vitamin $A$ the fontanelle was flat and the keratitis began to improve. Two months later the baby was reported to be in excellent health. In their other case a bulging anterior fontanelle was observed in a 3 -month-old infant with congenital absence of the bile ducts. Blood vitamin A was 34 i.u/100 ml. Within I week of the beginning of parenteral treatment with vitamin A the fontanelle was normal. In another infant with allergy to cow's milk, Bass (1956) found keratitis, widening of the skull sutures and a bulging anterior fontanelle, associated with complete absence of vitamin $A$ in the blood. Institution of parenteral therapy with vitamin A led to immediate improvement.

The problem still remains of the mechanism by which a deficiency of vitamin $A$ influences the cerebrospinal-fluid pressure. An increase in the cerebrospinal-fluid pressure must be due, if one excludes new growths, to a disproportion between the size of the brain and the skull, as suggested by Mellanby (1938-9) and Wolbach \& Bessey (I94I), or to increased production, underabsorption or interference with the free circulation of the cerebrospinal fluid. Disproportion between the brain and its bony coverings has been considered as unlikely to be the cause in the newborn rabbit (Millen, Woollam \& Lamming, 1954), and Bass \& Caplan (1955) were unable to accept such a growth disorganization as the origin of the increased cerebrospinalfluid pressures observed by them in infants suffering from gross hypovitaminosis A. Up to the present, evidence from experiments on rabbits and other animals points to an overactivity of the chorioid plexuses, unaccompanied by gross histological changes, as the most probable cause of the condition. The apparent fall in cerebrospinal-fluid pressure to normal within 2 days, noted by Bass \& Caplan, would also seem to favour this interpretation.

It is not clear how this view on the effect of vitamin A deficiency on the production of the cerebrospinal fluid can be reconciled with the reports of acute hydrocephalus in infants from the ingestion of massive doses of vitamin A. The increased intracranial pressure in these infants has also been attributed to an oversecretion of the cerebrospinal fluid by the chorioid plexuses (Marie \& Sée, I954). If the hypothesis put forward by Marie \& Sée is correct, and, as has been pointed out, other possibilities 
have not been excluded (Anonymous, I955), it would seem that there is a fine balance in the amount of vitamin $\mathrm{A}$ required by the chorioid plexuses for their normal functioning. Any gross alteration towards hypo- or hyper-vitaminosis may be sufficient to disturb this balance, with a consequent increase in the activity of the plexuses.

From the experiments reported in this paper, and from the accounts that have appeared elsewhere of increased cerebrospinal-fluid pressures in infants and experimental animals suffering from a deficiency of vitamin $\mathrm{A}$, it appears that an adequate supply of the vitamin is essential for the maintenance of normal cerebrospinal-fluid pressures. If insufficient vitamin $\mathrm{A}$ (or carotene) is present in the diet or if, as in the present investigation, the animal suffers from deprivation of vitamin A during its foetal development, the cerebrospinal-fluid pressure increases. There seems also to be strong evidence that a rapid reduction in the abnormal pressures can be brought about by the administration of vitamin $\mathrm{A}$.

SUMMARY

I. Intraventricular cerebrospinal-fluid pressures were measured in twenty-eight hydrocephalic young rabbits. In all but four animals ventriculography was also carried out.

2. After the pressure measurement the animals were given $10,000-20,000$ i.u. vitamin A acetate orally or subcutaneously.

3. The administration of the vitamin A led to a rapid fall in the cerebrospinal-fluid pressure and the fall generally continued until the pressure reached normal limits.

4. Six of the animals have survived for over 12 months and have remained in good health.

5. From these results it is suggested that the increased cerebrospinal-fluid pressure found in animals suffering from vitamin A deficiency is a direct consequence of the hypovitaminosis.

6. The findings are discussed in relation to previous observations on the relationship between hypovitaminosis $\mathrm{A}$ and increase of intracranial pressure.

Our thanks are due to Professor J. D. Boyd for his advice and encouragement. We wish also to express our indebtedness to $\mathrm{Dr}$ H. E. Daniels and Miss Jean Millar of the Statistical Laboratory, Cambridge, for the statistical analysis. Thanks are also due to Mr J. F. Crane and Miss I. Dean for technical assistance.

The investigation was supported by a grant from the Nuffield Foundation, which is gratefully acknowledged.

\section{REFERENCES}

Anonymous (1955). Brit. med. F. i, 715 .

Bass, M. H. (1956). Personal communication.

Bass, M. H. \& Caplan, J. (1955). F. Pediat. 47, 690.

Cornfeld, D. \& Cooke, R. E. (1952). Pediatrics, Springfield, xo, 33.

Eveleth, D. F., Bolin, D. W. \& Goldsby, A. I. (1949). Amer. F. vet. Res. 10, 250. 
Hart, E. B., Miller, W. S. \& McCollum, E. V. (1916). F. biol. Chem. 25, 239.

Helmboldt, C. F., Jungherr, E. L., Eaton, H. D. \& Moore, L. A. (r953). Amer. F. vet. Res. r4, 343.

Lamming, G. E., Woollam, D. H. M. \& Millen, J. W. (1954). Brit. F. Nutr. 8, ${ }^{6}{ }_{3}$.

Marie, J. \& Sée, G. (1954). Amer. F. Dis. Child. 87, 731 .

Mellanby, E. (1938-9). F. Physiol. 94, 380.

Mellanby, E. (1940-1). F. Physiol. 99, 467.

Millen, J. W. \& Woollam, D. H. M. (1956). F. Neurol. Psychiat. 19, 17.

Millen, J. W., Woollam, D. H. M. \& Lamming, G. E. (1954). Lancet, 267, 679.

Moore, L. A. \& Sykes, J. F. (1940). Amer. F. Physiol. r3o, 684.

Sorensen, D. K., Kowalczyk, T. \& Hentges, J. F. Jr. (1954). Amer. F. vet. Res. 15, 258.

Wolbach, S. B. \& Bessey, O. A. (194I). Arch. Path. (Lab. Med.) 32, 689.

Woollam, D. H. M. \& Millen, J. W. (1956). Brit. F. Nutr. 1o, 355.

\title{
The content of amino-acids in white flour and bread
}

\author{
By E. E. McDERMOTT and J. PACE \\ Research Association of British Flour-Millers, Cereals Research Station: \\ Old London Road, St Albans
}

(Received 12 Fune 1957)

Wheaten flour and bread provided, in $1955,27.8 \%$ of the total protein consumed in this country (Ministry of Agriculture, Fisheries and Food: National Food Survey Committee, 1957). Yet the information available on the amino-acid composition of such important sources of dietary protein is surprisingly inadequate. Thus at the present time no complete quantitative analysis of the amino-acids contained in the bread consumed in this country is available in the literature. Data given by Block \& Bolling (1945) are incomplete and refer to bread made in the U.S.A. For flour the position is better than with bread but is still unsatisfactory. Stokes, Gunness, Dwyer \& Caswell (I945) have analysed a patent flour, prepared in the U.S.A., for ten aminoacids including those essential for the growing rat. Baumgartner, Mather \& Stone (1946) have reported incomplete figures for whole wheat, milling fractions and an uncharacterized flour. Block \& Mitchell (1946-7) have given the content of thirteen amino-acids in whole wheat and gluten, and Barton-Wright \& Moran (1946) have determined the content of the essential amino-acids in whole wheat and in various fractions of the grain. Complete analyses have been reported more recently, by Kraut, Kofrányi, Telschow $\&$ Weber (I955), but these refer to two German flours with the relatively low nitrogen contents of $1 \cdot 42$ and $1.56 \%$.

The inadequacy of the data available to workers concerned with human nutrition has been emphasized by Hughes (1955) in reporting his calculations of the essential amino-acids available in the diets of the German children who took part in the experiments described in the report of Widdowson \& McCance (1954). For the figures for white bread he was obliged, in the absence of more relevant information at that time, to use the data of Stokes et al. (1945), obtained for a patent (U.S.A.) flour. This experience also illustrates the paucity of information on the effect, upon the total 